Article

\title{
Efficient Heterologous Production of Rhizopus oryzae Lipase via Optimization of Multiple Expression-Related Helper Proteins
}

\author{
Liangcheng Jiao, Qinghua Zhou, Zhixin Su and Yunjun Yan*(-) \\ Key Laboratory of Molecular Biophysics, the Ministry of Education, College of Life Science and Technology, \\ Huazhong University of Science and Technology, Wuhan 430074, China; jiaoliangcheng@gmail.com (L.J.); \\ qinghuazhou@hust.edu.cn (Q.Z.); xuzhixin5512@163.com (Z.S.) \\ * Correspondence: yanyunjun@hust.edu.cn; Tel.: +86-27-87792213
}

Received: 12 October 2018; Accepted: 25 October 2018; Published: 28 October 2018

check for updates

\begin{abstract}
This study is dedicated to efficiently produce Rhizopus oryzae lipase (ROL) by optimizing the expression of multiple expression-related helper proteins in Pichia pastoris. A series of engineered strains harboring different copy numbers of the ROL gene and different copies of the chaperone Pdi gene were first constructed to examine the influence of $P d i$ gene copy number on ROL production. The results showed that multiple copies of $P d i$ gene did not significantly improve ROL expression. Then, the effect of the co-overexpression of 10 expression-related helper proteins on ROL secretion was investigated by screening 20 colonies of each transformants. The data from shaking-flask fermentation suggested that Ssa4, Bmh2, Sso2, Pdi, Bip, Hac1, and VHb had positive effects on ROL expression. Subsequently, Ssa4, $\mathrm{Bmh} 2$, and $\mathrm{Sso} 2$, which all participate in vesicular trafficking and strongly promote ROL expression, were combined to further improve ROL production level. ROL activity of the screened strain GS115/5ROL-Ssa4-Sso2-Bmh2 4\# attained $5230 \mathrm{U} / \mathrm{mL}$. Furthermore, when the helper proteins Pdi, Bip, Hac1, and $\mathrm{VHb}$ were individually co-expressed with ROL in the strain GS115/5ROL-Ssa4-Sso2-Bmh2 4\#, lipase activity increased to $5650 \mathrm{U} / \mathrm{mL}$ in the strain GS115/5ROL-Ssa4-Sso2-Bmh2-VHb 9\#. Additionally, the maximum ROL activity of 41,700 U/mL was achieved in a $3 \mathrm{~L}$ bioreactor for high-density fermentation via a sorbitol-methanol co-feeding strategy, reaching almost twofold the value of the initial strain GS115/pAO $\alpha-5$ ROL 11\#. Thus, the strategies in this study significantly increased ROL expression level, which is of great potential for the large-scale production of ROL in P. pastoris.
\end{abstract}

Keywords: Rhizopus oryzae lipase; heterologous overexpression; Pichia pastoris; helper proteins; high-density fermentation

\section{Introduction}

Lipases (triacylglycerol acylhydrolases, EC 3.1.1.3) can catalyze hydrolysis, ester synthesis, and trans-esterification processes at the oil-water interface [1,2]. These special functions of lipases have endowed them with a great biotechnological potential. They are now widely used in a variety of industrial areas, such as for flavor, detergents, pharmaceutical, bioremediation, and biodiesel preparation [3,4]. As a noticeable enzyme, Rhizopus oryzae lipase (ROL) possesses strong 1-, 3 -regiospecificity, which has been extensively used to produce biodiesel $[5,6]$. However, as known, the yield of ROL in the original R. oryzae strain is too low to meet the huge demands of the industry. Recently, ROL has achieved relatively high secretion levels via efficient heterologous expression in Pichia pastoris $[7,8]$, but its expression level still needs to be further improved so as to greatly reduce the production cost. Thus, it is urgent to develop more effective strategies. 
The P. pastoris expression system is widely applied for high-level expression of various heterologous proteins owing to its ease of genetic operation, its ability to grow to a high cell concentration under low nutritional conditions, its capability to execute complex eukaryotic post-translational modifications, its multiple promoters available, especially its alcohol oxidase 1 promoter (pAOX1), which is tightly regulated by methanol [9-11]. As known, the correct secretion of proteins must undergo the processes of transcription, translation, folding, and secretion. A series of factors can affect the expression level of proteins in P. pastoris, including promoter strength, gene dosage, secretion signal, protein translation, protein assembly, protein secretion, and fermentation conditions [12-14]. Among them, one of the most effective strategies to enhance protein production is to screen strains containing multiple copies of the target gene [14,15]. Nevertheless, as the gene dosage increases, recombinant proteins may excessively accumulate in the endoplasmic reticulum (ER), causing cellular stress and then activating the unfolded protein response (UPR), which would trigger the splicing of Hac1 mRNA and generate the transcriptional activator Hac1 [16,17]. Next, the UPR activator Hac1 would reduce cellular stress by regulating several downstream genes involving in protein folding and transport, ER quality control, and ER-associated degradation (ERAD) [16,18]. However, the cells' intrinsic regulatory mechanisms do not always remove cell stress effectively. To further increase protein secretion levels, some reported strategies trying to aid proteins folding as well as to reduce ER stress, have successfully achieved a higher level of gene expression. Among these, are the co-expression of the chaperones immunoglobulin-binding protein (Bip), protein disulfide isomerase (Pdi), and/or calnexin-like protein 1 (Cne1) [19,20] and the increased expression of the UPR activator Hac1 [7] and of ER oxidoreduction 1 (Ero1) [21]. In addition, the phosphomannomutase Sec53, which participates in both protein folding and ER quality control, has also been successfully employed to enhance protein production [20].

Protein secretion must go through the protein transport process, which also affects protein secretion. Several transport-related proteins, such as the cytosolic chaperone Ssa4, which is responsible for the transport of target nascent proteins to the ER membrane [22], and 14-3-3 protein Bmh2, which is involved in protein exit from the ER [23], have been reported to increase protein expression levels in P. pastoris [20,22]. Another secretion helper factor, Sso2, acting as one of the soluble $\mathrm{N}$-ethylmaleimide-sensitive factor attachment protein receptors and helping the fusion of secretory vesicles at the plasma membrane [24], could also achieve the purpose of enhancing protein production [22].

When growing under high cell density conditions, P. pastoris requires a large amount of oxygen to maintain cell growth. In addition, oxygen solubility would be gradually reduced as the cell density increases [25]. So, oxygen intake becomes a bottleneck in protein expression under high-density conditions. To alleviate this problem, vitreoscilla hemoglobin $(\mathrm{VHb})$ from Vitreoscilla stercoraria, which can facilitate oxygen delivery, has been used to promote protein expression [26].

Although the above-mentioned strategies have successfully increased the expression levels of some proteins, they cannot be effective for all proteins. For example, the secretion of glucose oxidase (GOD) was remarkably enhanced via co-expression of Sec53 [20]. However, the overexpression of Sec53 did not increase the production of $\Delta^{9}$-tetrahydrocannabinolic acid synthase [27]. Thus, the effectiveness of these strategies for the expression of a specific protein, including ROL, may be uncertain. So far, some strategies have been successfully applied to enhance ROL production in P. pastoris. For example, the ROL production level was effectively improved by co-overexpression of Ero1 and Pdi [8]. The co-expression of Saccharomyces cerevisiae Hac1 resulted in a threefold enhancement in ROL expression levels [7]. Moreover, ROL activity was improved 15.8-fold via a strategy combining the optimization of gene copy number with the co-expression of ERAD-related proteins [14]. However, there is no systematical optimization of the above-mentioned expression-related helper proteins to improve ROL expression levels. This optimization could help us to find a more appropriate expression strategy leading to a significant increase in ROL production. 
Therefore, in this study, based on a previously constructed gene copy number-optimized recombinant strain GS115/pAO $\alpha$-5ROL 11\# [14], we first investigated the effect of 10 helper factors on ROL production in P. pastoris. Then, the helper genes which showed a positive effect on ROL production were selected and combined together to further enhance ROL secretion levels. Moreover, a $3 \mathrm{~L}$ high-density fermentation of the optimized strains was performed to test the maximum capability of ROL secretion.

\section{Results}

\subsection{Influence of the Co-Expression of Different Copies of Pdi on ROL Production}

Previously, we created a series of strains harboring different gene copy numbers of $R O L$ and found that $R O L$ gene dosage had an important effect on ROL expression [14]. To investigate the effect of the gene copy number of the expression-related helper factors on ROL production, Pdi, being an important ER chaperone, was selected as the model to achieve this goal.

First, the PmeI-linearized plasmids pPICZA-Pdi and pPICZA (control) were separately introduced into GS115/pAO $\alpha$-nROL $(n=1,2,3, \ldots 5)$. Twenty colonies of each strain (GS115/nROL-Pdi, $n=1,2,3, \ldots 5$ ) were picked out for shake-flask fermentation. ROL activity was determined after $96 \mathrm{~h}$ methanol induction (Figure 1). To ensure that only one copy of pPICZA-Pdi was inserted into the genomic DNA of each transformants, the gene copy number of the strains was measured by RT-qPCR. As expected, co-expression of Pdi increased the level of ROL secretion. Interestingly, it seemed that as $R O L$ gene copy number increased, the effect of Pdi on the secretion of ROL was less pronounced.

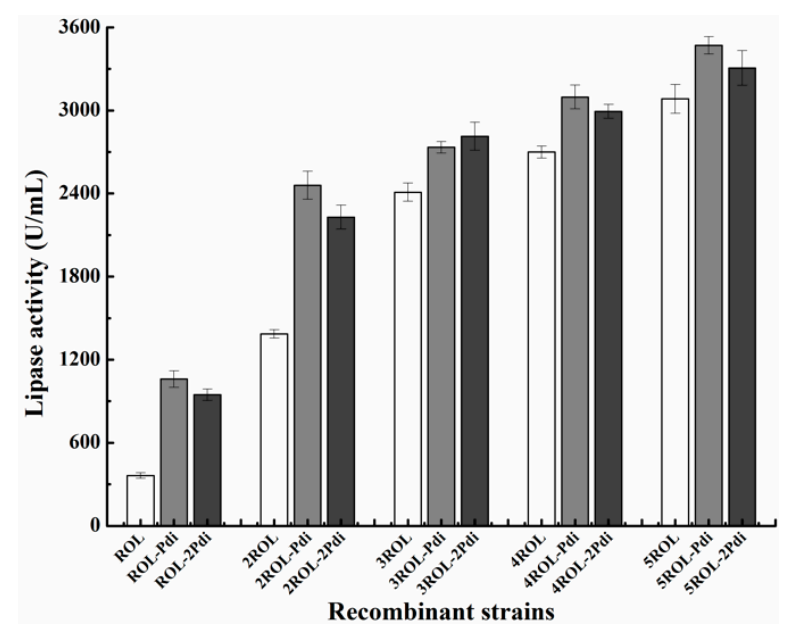

Figure 1. Rhizopus oryzae lipase (ROL) activity of the recombinant strains harboring different copy numbers of $R O L$ gene and protein disulfide isomerase $(P d i)$ gene. All values are presented as the mean \pm standard deviation of three independent experiments.

Next, to understand whether increasing the copy number of Pdi gene could further increase the expression level of ROL, the plasmid pPIC3.5K-Pdi was linearized by SacI and introduced into GS115/nROL-Pdi $(n=1,2,3, \ldots 5)$ via electroporation. After determining the gene copy number via RT-qPCR, the strains GS115/nROL-2Pdi $(n=1,2,3, \ldots 5)$ harboring two copies of Pdi gene were cultured in shaking flasks. Surprisingly, when Pdi gene copy number further increased from one to two, ROL expression level no longer increased and, even, decreased (Figure 1). The gene copy number of the recombinant strains is presented in Table 1. 
Table 1. Recombinant strains with different copy numbers of the Pdi gene and ROL gene ${ }^{1}$.

\begin{tabular}{ccc}
\hline \multirow{2}{*}{ Strains } & \multicolumn{2}{c}{ Gene Copy Number } \\
\cline { 2 - 3 } & ROL & Pdi \\
\hline GS115 (control) & 0 & 1 \\
GS115/ROL-Pdi & 1 & 2 \\
GS115/2ROL-Pdi & 2 & 2 \\
GS115/3ROL-Pdi & 3 & 2 \\
GS115/4ROL-Pdi & 4 & 2 \\
GS115/5ROL-Pdi & 5 & 2 \\
GS115/ROL-2Pdi & 1 & 3 \\
GS115/2ROL-2Pdi & 2 & 3 \\
GS115/3ROL-2Pdi & 3 & 3 \\
GS115/4ROL-2Pdi & 4 & 3 \\
GS115/5ROL-2Pdi & 5 & 3 \\
\hline 1 The copy number of Pdi minus one (endogenous gene) is the copy number of the inserted gene.
\end{tabular}

\subsection{Effect of Co-Expressing a Single Helper Gene on ROL Expression}

To investigate the influence of co-expressing a single helper gene on ROL expression, pPICZA (control) and pPICZA-derived plasmids harboring different helper genes were firstly electrotransformed into the strain GS115/pAO $\alpha-5 R O L$ 11\#. As shown in Figure 2, the co-expression of Ssa4, Bmh2, Sso2, Pdi, Bip, Hac1, and VHb showed positive effects on ROL production. Among them, the overexpression of Ssa4, Sso2, Bmh2, and Bip resulted in $45 \%, 39 \%, 32 \%$, and $22 \%$ enhancement of ROL secretion level, respectively. The recombinant strain GS115/5ROL-Ssa4 12\# displayed the maximum ROL activity at $4470 \mathrm{U} / \mathrm{mL}$. However, several helper factors, such as Ero1, Sec53, and Cne1, did not improve ROL activity in the strain GS115/pAO $\alpha-5$ ROL 11\#.

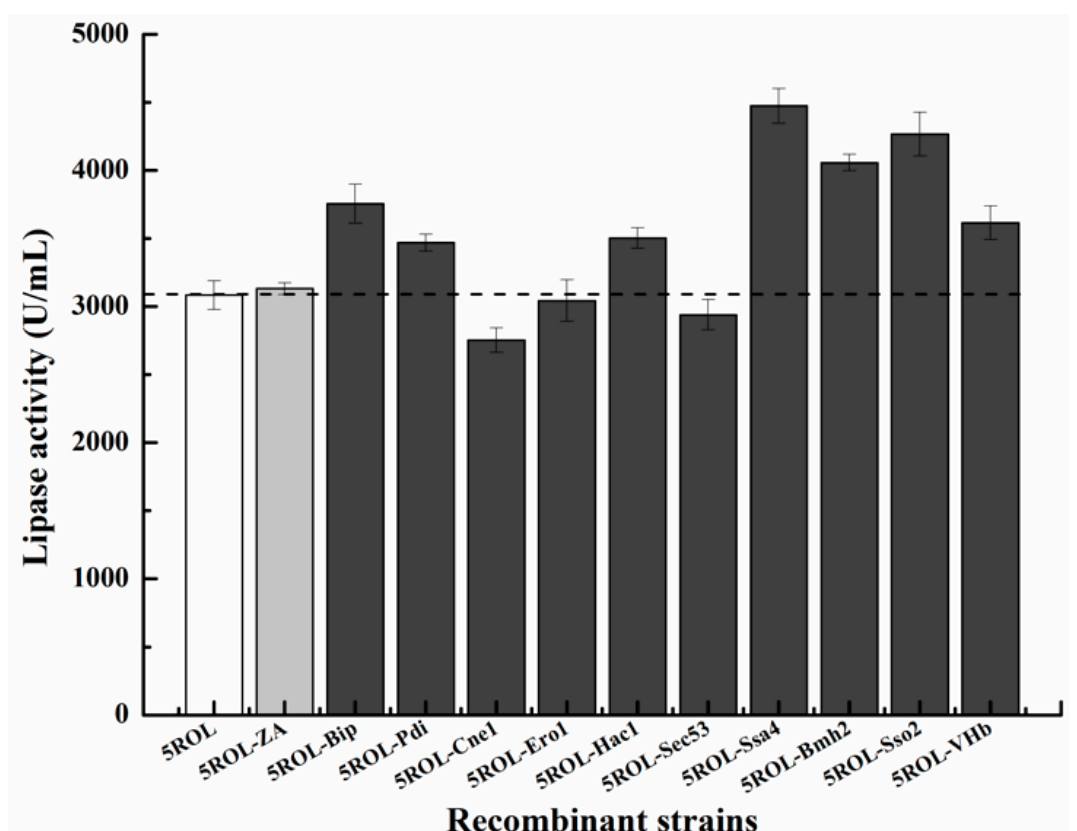

Figure 2. Effect of co-expressing helper proteins on ROL production in the strain GS115/pAO $\alpha-5 R O L$ 11\#. The dotted line indicates the lipase activity of the initial strain GS115/pAO $\alpha-5$ ROL 11\#. All values are presented as the mean \pm standard deviation of three independent experiments.

\subsection{Co-Expressing Multiple Helper Genes to Enhance ROL Secretion}

Based on the above results, co-expression of helper genes (Ssa4, Bmh2, and Sso2) participating in the protein secretion process significantly improved ROL production, suggesting that the efficiency 
of protein trafficking through the secretory pathway of the strain GS115/pAO $\alpha-5 R O L$ 11\# might greatly limit ROL production. To achieve even higher ROL production, the helper genes Ssa4, Bmh2, and Sso2 were first co-expressed together with ROL in GS115/pAO $\alpha-5 R O L$ 11\#. The plasmids pPIC3.5K-Ssa4-Bmh2, pPIC3.5K-Ssa4-Sso2, pPIC3.5K-Sso2-Bmh2, and pPIC3.5K-Ssa4-Sso2-Bmh2, which harbored multiple helper gene expression cassettes, were linearized by SalI and then electroporated into the strain GS115/pAO $\alpha-5$ ROL 11\#. The lipase activities of the obtained transformants were investigated in shaking flasks (Figure 3a). The activities of the recombinant strains GS115/5ROL-Sso2-Bmh2 13\#, GS115/5ROL-Ssa4-Bmh2 18\#, and GS115/5ROL-Ssa4-Sso2 11\# respectively reached $4730 \mathrm{U} / \mathrm{mL}, 4860 \mathrm{U} / \mathrm{mL}$, and $4930 \mathrm{U} / \mathrm{mL}$, values that were all higher than those of the strains co-expressing only one helper gene. In addition, the highest ROL activity of $5230 \mathrm{U} / \mathrm{mL}$ was obtained in the strain GS115/5ROL-Ssa4-Sso2-Bmh2 4\#, indicating that Ssa4, Bmh2, and Sso2 had a synergistic effect on ROL secretion.

In an attempt to further increase ROL expression level, other helper genes that also showed a positive effect on ROL expression, namely, Pdi, Bip, $H a c 1$, and $V H b$, were also co-expressed with ROL in the strain GS115/5ROL-Ssa4-Sso2-Bmh2 4\#. After induction for $96 \mathrm{~h}$ by methanol in shaking flasks, the fermentation supernatants of the recombinants were collected for the lipase assay. As shown in Figure $3 \mathrm{~b}$, only co-expression of $\mathrm{VHb}$ led to a slight improvement of ROL production. The lipase activity of the highest secreting strain, GS115/5ROL-Ssa4-Sso2-Bmh2-VHb 9\#, reached $5650 \mathrm{U} / \mathrm{mL}$, which was $83 \%$ higher than that obtained in GS115/pAO $\alpha-5$ ROL $11 \#$.

a

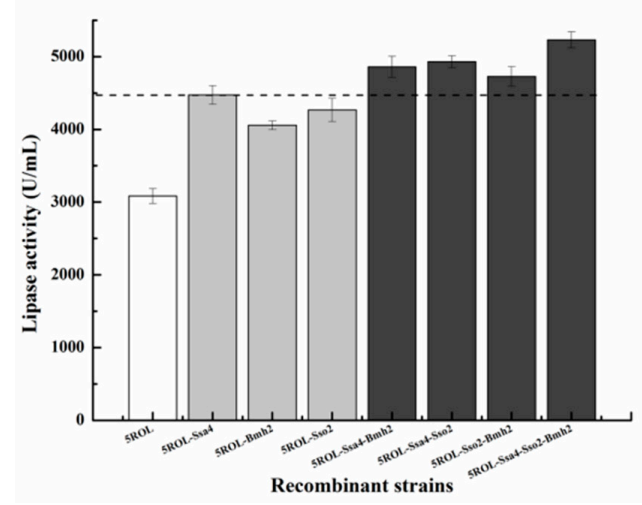

b

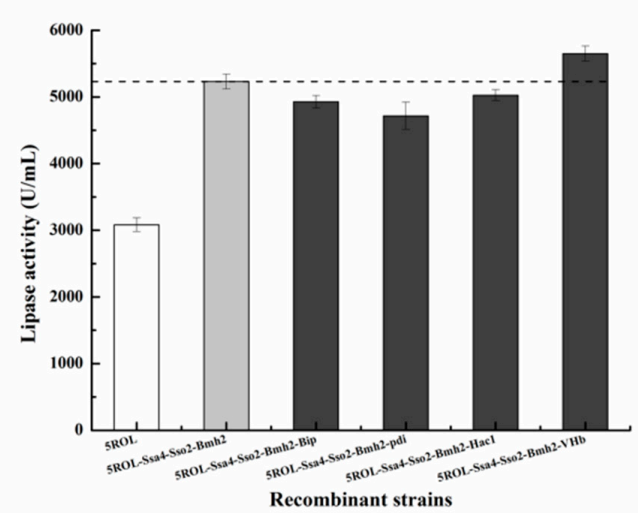

Figure 3. Cultivation properties of the recombinant strains in shaking flasks. (a) Effect of co-expressing multiple trafficking-related genes on ROL production in the strain GS115/pAO $\alpha$-5ROL 11\#. The dotted line indicates the lipase activity of the strain GS115/5ROL-Ssa4 12\#. (b) Effect of co-expressing the helper proteins Bip, Pdi, Hac1, and VHb on ROL production in the strain GS115/5ROL-Ssa4-Sso2-Bmh2 4\#. The dotted line indicates the lipase activity of the strain GS115/5ROL-Ssa4-Sso2-Bmh2 4\#. Data represent the mean \pm standard deviation of three independent experiments.

\subsection{High-Cell-Density Fermentation in a 3 L Bioreactor}

To obtain an even higher ROL production, the engineered strain GS115/5ROL-Ssa4-Sso2-Bmh2 4\# was cultivated in a $3 \mathrm{~L}$ fermenter via a sorbitol-methanol co-feeding strategy [28]. The dissolved oxygen value was controlled at $20-50 \%$. As shown in Figure $4 \mathrm{a}$, the lipase activity of the strain GS115/5ROL-Ssa4-Sso2-Bmh2 4\# achieved the maximum value after $122 \mathrm{~h}$ of fermentation, reaching $36,700 \mathrm{U} / \mathrm{mL}$, which was $79 \%$ higher than that observed in the initial strain GS115/pAO $\alpha-5 \mathrm{ROL}$ 11\# [14]. In addition, the ROL expression level of the strain GS115/5ROL-Ssa4-Sso2-Bmh2 4\# was even higher than that of the strain co-expressing two ERAD-related genes in GS115/5ROL-Hrd1-Ubc1 $1 \#(33,900 \mathrm{U} / \mathrm{mL})$ [14]. Furthermore, the total protein concentration increased to $7.22 \mathrm{~g} / \mathrm{L}$, and the highest dry cell weight (DCW) and the optical density at $600 \mathrm{~nm}\left(\mathrm{OD}_{600 \mathrm{~nm}}\right)$ reached $123 \mathrm{~g} / \mathrm{L}$ and 422, respectively. These results indicate that the helper factors Ssa4, Bmh2, and Sso2 had a great positive effect on ROL expression in P. pastoris. 

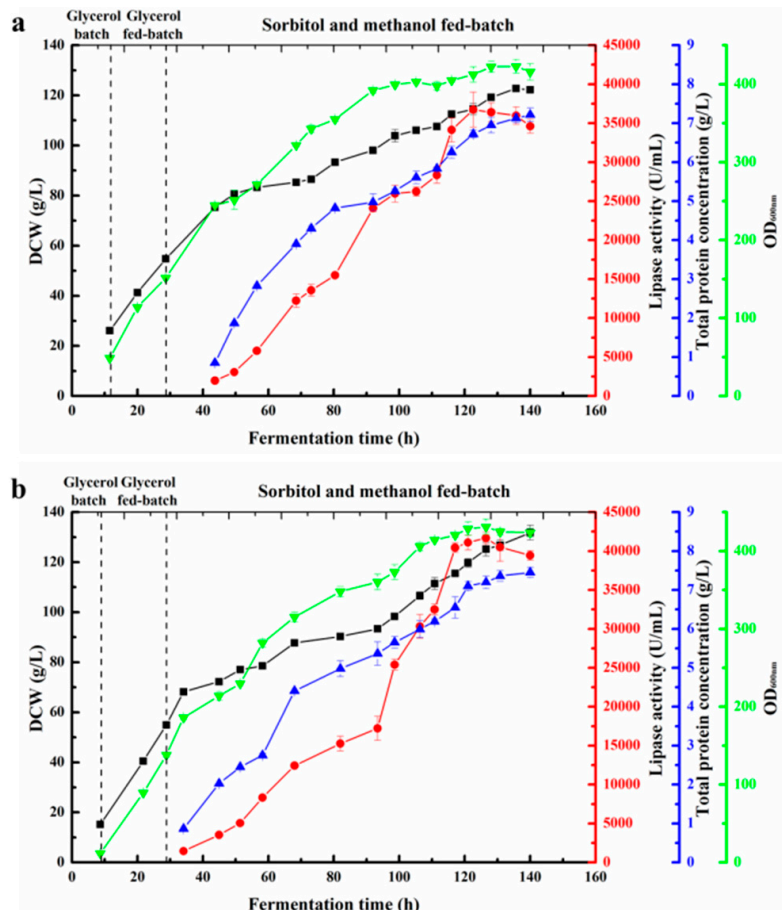

Figure 4. Time course of dry cell weight (DCW) (black square), ROL activity (red circle), total protein concentration (blue triangle), and optical density at $600 \mathrm{~nm}\left(\mathrm{OD}_{600 \mathrm{~nm}}\right)$ (green inverted triangle) during a 3 L high-density fermentation of the strains (a) GS115/5ROL-Ssa4-Sso2-Bmh2 4\# and (b) GS115/5ROL-Ssa4-Sso2-Bmh2-VHb 9\#. Data represent the mean \pm standard deviation of three independent experiments.

To investigate the effect of $\mathrm{VHb}$ on ROL production, a fed-batch study of GS115/5ROLSsa4-Sso2-Bmh2-VHb 9\# was conducted under the same cultivation conditions. The results showed that co-expression of $\mathrm{VHb}$ further improved ROL activity to $41,700 \mathrm{U} / \mathrm{mL}$ and increased the total protein concentration to $7.45 \mathrm{~g} / \mathrm{L}$ after $126 \mathrm{~h}$ of cultivation (Figure $4 \mathrm{~b}$ ). The lipase activity was $14 \%$ higher than that of GS115/5ROL-Ssa4-Sso2-Bmh2 4\#. In addition, compared with the strain GS115/5ROL-Ssa4-Sso2-Bmh2 4\#, further co-expression of VHb with ROL slightly increased cell growth, and DCW and $\mathrm{OD}_{600 \mathrm{~nm}}$ increased to $132 \mathrm{~g} / \mathrm{L}$ and 431 , respectively, at the end of the fermentation. Sodium dodecyl sulfate polyacrylamide gel electrophoresis (SDS-PAGE) analyses of the supernatants during high-density cultivation are shown in Figure 5.

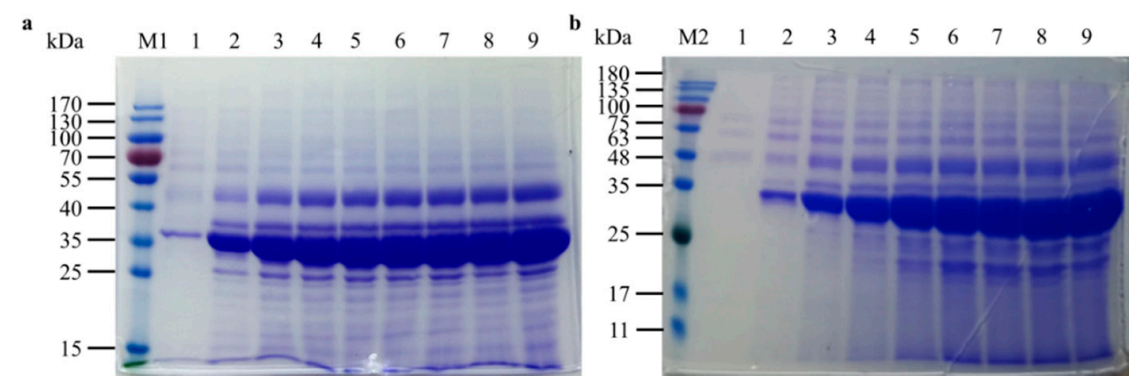

Figure 5. Time course of sodium dodecyl sulfate polyacrylamide gel electrophoresis (SDS-PAGE) analyses of extracellular proteins during high-density cultivation in a $3 \mathrm{~L}$ fermenter of the following strains: (a) GS115/5ROL-Ssa4-Sso2-Bmh2 4\#: lanes 1-9, $12.5 \mu \mathrm{L}$ of culture supernatant in the $3 \mathrm{~L}$ fermenter after $43,50,68,73,92,99,105,116$, and $128 \mathrm{~h}$ of fermentation, respectively. Lane M1, low-molecular-weight marker; (b) GS115/5ROL-Ssa4-Sso2-Bmh2-VHb 9\#: lanes 1-9, $12.5 \mu \mathrm{L}$ of culture supernatant in the $3 \mathrm{~L}$ fermenter after $29,45,68,82,93,110,117,126$, and $140 \mathrm{~h}$ of cultivation, respectively. Lane M2, low-molecular-weight marker. 


\section{Discussion}

ROL, an important industrial lipase, is often used to produce biodiesel [6]. In order to reduce the cost of industrial applications, several researchers have employed multiple molecular genetic strategies and fermentation techniques to increase its production level $[7,8,14]$. Yu et al. [29] employed an approach consisting in replacing the pro-peptide of ROL with Rhizopus chinensis lipase pro-peptide to promote ROL expression, and the maximal lipase activity reached $4050 \mathrm{U} / \mathrm{mL}$ in a $7 \mathrm{~L}$ fermenter. Besides, ROL production yield was further enhanced via co-expression of Ero1 and Pdi, followed by optimization of the $\mathrm{NH}_{4}{ }^{+}$concentration in a high-density fermentation environment, and ROL activity attained 12,019 $\mathrm{U} / \mathrm{mL}$ [8]. In addition, intracellular co-expression of the S. cerevisiae UPR transcription factor Hac1 as well as damage of the Gas1 gene resulted in about a seven-fold enhancement in the production level of ROL [7]. Moreover, ROL expression was improved 15.8-fold by combining the optimization of gene copy number with the co-expression of ERAD-related proteins, reporting the highest level of 33,900 U/mL in a $3 \mathrm{~L}$ fermenter [14]. However, the production level of ROL should be further increased to meet the huge industrial demands. In the present study, more strategies have been attempted and successfully provided a higher ROL activity.

Many researchers have reported that the overexpression of exogenous genes in P. pastoris might result in the accumulation of unfolded proteins that cause ER stress and activate the UPR $[16,17,30]$. Therefore, overloading foreign proteins might represent an important bottleneck for high-level protein expression. To alleviate this problem and obtain even higher protein productions, several strategies focused on aiding protein folding by co-producing the UPR activator Hac1 or co-overexpressing ER chaperones, such as Ero1, Pdi, and Bip [7,13,20,21]. Additionally, the production level of foreign genes could also be improved by co-overexpression of proteins involved in transport pathways [20]. However, the same strategy might have different effects on various target proteins and in various strains. In addition, it is not clear which chaperone or helper protein may be helpful in improving ROL expression. Moreover, although the copy number of exogenous genes is one of the key parameters to consider when trying to optimize protein production in P. pastoris, it is not certain that the copy number of helper genes is equally important. Therefore, before attempting to co-express multiple potential helper proteins with ROL to increase its expression level, the important ER chaperone Pdi was selected as a representative chaperone to investigate the effect of different copies of a helper gene on ROL production level.

Firstly, a series of strains harboring different copies of $R O L$ gene and different copies of Pdi gene were generated via two rounds of electrotransformation. As shown in Figure 1, the expression levels of ROL were obviously improved by co-expression of Pdi. However, it can also be seen that ROL activity increased slightly with the increment of $R O L$ gene copies. Moreover, compared with the strains co-expressing one copy of Pdi gene, increasing the dosage of Pdi gene in recombinant strains resulted in a very little effect on ROL secretion, even in a negative effect. These results are similar to those previously reported [13]. A possible explanation is that the gene transcription level under the control of pAOX1 was already very high, and a single copy of Pdi gene was sufficient to aid protein folding. Besides, the strains harboring multiple copies of $P d i$ gene would produce higher levels of Pdi proteins, which would compete with the target proteins for transcription, translation, and other secretion processes. Additionally, it was reported by Schwarzhans et al. [31] that a higher gene copy number does not necessarily result in high production.

On the basis of the above results, the strain with multiple copies of a helper gene is not necessary for the purpose of enhancing ROL production level. Moreover, multiple plasmid integration events occur naturally at an extremely low frequency $(\sim 1 \%)$ during the transformation process in P. pastoris [32]. Hence, when investigating the effect of co-expressing helper proteins on ROL activity, 20 colonies of each strain were randomly selected, without a post-transformational vector amplification (PTVA) $[33,34]$ process, to achieve this goal, and these colonies would obviously include the single-copy transformants. As shown in Figure 2, individual co-overexpression of Ssa4, Sso2, Bmh2, and Bip with ROL greatly increased ROL expression, to levels about $45 \%, 39 \%, 32 \%$, and $22 \%$ higher, respectively, 
than that of the initial strain GS115/pAO $\alpha-5 R O L$ 11\#. Among them, co-expression of Sso2 with ROL in strain GS115/5ROL-Ssa4 12\# produced the maximum ROL activity of $4470 \mathrm{U} / \mathrm{mL}$. Besides, co-expressing Pdi, Hac1, and $\mathrm{VHb}$ individually also had positive effects on ROL production. However, Ero1, Sec53, and Cne1 did not improve the ROL expression level. These results are in contrast with those reported, which showed that the overexpression of Ero1 increased the production of Candida rugosa lipase Lip1 in P. pastoris [21] and the co-production of Sec53 and Cne1 greatly enhanced the expression level of GOD [20], suggesting that the role of helper genes strongly depended on the target protein or the target strain. Hence, it is worth screening different key helper genes for the purpose of increasing a target protein's secretion level.

The results of co-expressing a single helper protein with ROL indicated that the genes $S s a 4, B m h 2$, and $\mathrm{Sso2}$, which are involved in vesicular trafficking, had a significant influence on ROL production. To explore whether co-expression of multiple trafficking-related genes could further enhance the ROL expression level, pPIC3.5K-derived plasmids harboring multiple trafficking-related genes were constructed and electrotransferred into the strain GS115/pAO $\alpha-5 \mathrm{ROL} 11 \#$ to achieve this goal. As shown in Figure 3a, the trafficking-related genes did have a synergistic effect on ROL production as expected, with ROL activities reaching $4730 \mathrm{U} / \mathrm{mL}, 4860 \mathrm{U} / \mathrm{mL}$, and $4930 \mathrm{U} / \mathrm{mL}$ in the recombinant strains GS115/5ROL-Sso2-Bmh2 13\#, GS115/5ROL-Ssa4-Bmh2 18\#, and GS115/5ROL-Ssa4-Sso2 11\#, respectively. Moreover, co-expression of Sso2, Bmh2, and Ssa4 with ROL in the strain GS115/5ROL-Ssa4-Sso2-Bmh2 4\# produced the highest ROL activity of $5230 \mathrm{U} / \mathrm{mL}$ in shake-flask fermentation, which was about $70 \%$ higher than that obtained in the initial strain GS115/pAO $\alpha-5 \mathrm{ROL}$ 11\#. These results imply that protein trafficking through the transport pathway might be a bottleneck for high-level expression of ROL in the strain of GS115/pAO $\alpha$-5ROL 11\#.

To further increase the ROL production level, the remnant helper proteins (Bip, Pdi, Hac1, and $\mathrm{VHb}$ ), which also showed a positive effect on ROL expression, were respectively co-expressed with ROL in strain GS115/5ROL-Ssa4-Sso2-Bmh2 4\# via a new round of electroporation. Unfortunately, the results of shake-flask fermentation demonstrated that co-expression of these helper factors (Bip, Pdi, and Hac1, which are involved in improving protein folding efficiency) did not further improve ROL expression level (Figure 3b). These results might be due to the fact that ROL production in strain GS115/5ROL-Ssa4-Sso2-Bmh2 4\# is improved via enhancing protein trafficking, and, as the efficiency of the protein transport process increases, the proteins would leave the ER faster, which might then help cells reduce ER stress; subsequently, the expression of ROL might present a new bottleneck, so that a continuous increase of the protein folding function to reduce ER stress becomes less effective. However, co-expression of $\mathrm{VHb}$ along with ROL in the recombinant strain GS115/5ROL-Ssa4-Sso2-Bmh2-VHb 9\# slightly improved ROL activity to $5650 \mathrm{U} / \mathrm{mL}$, which is about an $83 \%$ improvement compared to the initial strain (GS115/pAO $\alpha-5 \mathrm{ROL} 11 \#)$ and might be attributed to the fact that $\mathrm{VHb}$ could promote cell growth in an environment with a high cell density.

High-density fermentation of strains GS115/5ROL-Ssa4-Sso2-Bmh2 4\# and GS115/5ROLSsa4-Sso2-Bmh2- $\mathrm{VHb}$ 9\# were performed in a $3 \mathrm{~L}$ fermenter via a sorbitol-methanol co-feeding strategy (Figure 4). Co-expression of Ssa4, Bmh2, and Sso2 with ROL in strain GS115/5ROL-Ssa4-Sso2-Bmh2 4\# significantly enhanced ROL production level, the lipase activity reached $36,700 \mathrm{U} / \mathrm{mL}$, and the total protein concentration attained $7.22 \mathrm{~g} / \mathrm{L}$. Moreover, when $\mathrm{VHb}$ was co-expressed with ROL in strain GS115/5ROL-Ssa4-Sso2-Bmh2-VHb 9\#, ROL activity and protein concentration further increased to $41,700 \mathrm{U} / \mathrm{mL}$ and $7.45 \mathrm{~g} / \mathrm{L}$. Additionally, the maximum DCW (132 g/L) and $\mathrm{OD}_{600 \mathrm{~nm}}(431)$ were also slightly higher than those in the strain GS115/5ROL-Ssa4-Sso2-Bmh2 4\#. These results indicated that co-expression of $\mathrm{VHb}$ could exert a positive effect on cell growth and, in return, improve the secretion level of ROL. Overall, the combined strategies used in this study resulted in a twofold increase in ROL expression compared to the initial strain GS115/pAO $\alpha$-5ROL 11\# (20,500 U/mL) [14]. 


\section{Materials and Methods}

\subsection{Strains, Plasmids, and Media}

P. pastoris GS115, Escherichia coli Top10 cells, and the plasmids pPIC3.5K and pPICZA were bought from Invitrogen (Carlsbad, CA, USA). Recombinant P. pastoris strains GS115/pAO $\alpha$-nROL $(n=1,2,3$, ... 5) were constructed previously [14]. The plasmid pPIC3.5K-VHb was stored in our laboratory [26]. The pMD19-T simple vector, PrimeStar HS DNA polymerase, restriction enzymes, and T4 DNA ligase were purchased from TaKaRa (Dalian, China). Real-time quantitative PCR (RT-qPCR) reagents and materials were commercially obtained from Tiangen Biotechnology (Beijing, China). All strains, plasmids, and primers used in this study are listed in Tables 2 and 3.

Table 2. Strains and plasmids used in this study.

\begin{tabular}{|c|c|c|}
\hline Plasmids/Strains & Description & References \\
\hline pPIC3.5K & Intracellular expression vector, His 4 gene and $\operatorname{Kan}$ gene $\left(\mathrm{G} 418^{\mathrm{r}}\right)$ & Invitrogen \\
\hline pPICZ-Ssa4 & pPICZA derivative, carrying $S s a 4$ gene expression cassette & This study \\
\hline pPICZ-Bip & pPICZA derivative, carrying Bip gene expression cassette & This study \\
\hline pPICZ-Cne1 & pPICZA derivative, carrying Cne1 gene expression cassette & This study \\
\hline pPICZ-Bmh2 & pPICZA derivative, carrying $B m h 2$ gene expression cassette & This study \\
\hline pPICZ-Sso2 & pPICZA derivative, carrying $S$ so 2 gene expression cassette & This study \\
\hline pPICZ-Hac1 & pPICZA derivative, carrying Hac1 gene expression cassette & This study \\
\hline pPICZ-Pdi & pPICZA derivative, carrying Pdi gene expression cassette & This study \\
\hline pPICZ-VHb & pPICZA derivative, carrying $V H b$ gene expression cassette & This study \\
\hline pPIC3.5K-Pdi & pPIC3.5K derivative, carrying Pdi gene expression cassette & This study \\
\hline E. coli Top10 & $\begin{array}{l}\text { F-, } \operatorname{mcr} A \Delta(\text { mrr-hsd RMS-mcrBC), } \phi 80, \text { lacZ } \Delta M 15, \Delta l a c X 74, \text { rec } A 1, \\
\text { ara } \Delta 139 \Delta \text { (ara-leu)7697, gall, galK, rps, }(\text { StrR }) \text { endA1, nup }\end{array}$ & Invitrogen \\
\hline P. pastoris GS115 & Host strain (his $4^{-}$, Mut $^{+}$) & Invitrogen \\
\hline $\mathrm{GS} 115 / \mathrm{pAO} \alpha-\mathrm{ROL}$ & GS115 harboring one copy of ROL gene & [14] \\
\hline $\mathrm{GS} 115 / \mathrm{pAO} \alpha-2 \mathrm{ROL}$ & GS115 harboring two copies of ROL gene & {$[14]$} \\
\hline $\mathrm{GS} 115 / \mathrm{pAO} \alpha-3 \mathrm{ROL}$ & GS115 harboring three copies of ROL gene & [14] \\
\hline $\mathrm{GS} 115 / \mathrm{pAO} \alpha-4 \mathrm{ROL}$ & GS115 harboring four copies of ROL gene & [14] \\
\hline $\mathrm{GS} 115 / \mathrm{pAO} \alpha-5 \mathrm{ROL}$ & GS115 harboring five copies of ROL gene & [14] \\
\hline GS115/ROL-Pdi & GS115/pAO $\alpha$-ROL harboring pPICZ-Pdi & This study \\
\hline GS115/2ROL-Pdi & GS115/pAO $\alpha-2$ ROL harboring pPICZ-Pdi & This study \\
\hline GS115/3ROL-Pdi & GS115/pAO $\alpha-3 R O L$ harboring pPICZ-Pdi & This study \\
\hline GS115/5ROL-Bip & GS115/pAO $\alpha-5$ ROL harboring pPICZ-Bip & This study \\
\hline GS115/5ROL-Cne1 & GS115/pAO $\alpha-5 R O L$ harboring pPICZ-Cne1 & This study \\
\hline GS115/5ROL-Ero1 & GS115/pAO $\alpha-5$ ROL harboring pPICZ-Ero1 & This study \\
\hline GS115/5ROL-Sec53 & GS115/pAO $\alpha-5$ ROL harboring pPICZ-Sec53 & This study \\
\hline GS115/5ROL-Bmh2 & GS115/pAO $\alpha-5$ ROL harboring pPICZ-Bmh2 & This study \\
\hline GS115/5ROL-Sso2 & GS115/pAO $\alpha-5$ ROL harboring pPICZ-Sso2 & This study \\
\hline GS115/5ROL-Hac1 & GS115/pAO $\alpha-5$ ROL harboring pPICZ-Hac1 & This study \\
\hline GS115/5ROL-VHb & GS115/pAO $\alpha-5$ ROL harboring pPICZ-VHb & This study \\
\hline GS115/5ROL-Sso2-Bmh2 & GS115/pAO $\alpha-5$ ROL harboring pPIC $3.5 \mathrm{~K}-\mathrm{Sso} 2-\mathrm{Bmh} 2$ & This study \\
\hline GS115/5ROL-Ssa4-Bmh2 & GS115/pAO $\alpha-5$ ROL harboring pPIC3.5K-Ssa4-Bmh2 & This study \\
\hline GS115/5ROL-Ssa4-Sso2 & GS115/pAO $\alpha-5 R O L$ harboring pPIC3.5K-Ssa4-Sso2 & This study \\
\hline GS115/5ROL-Ssa4-Sso2-Bmh2 & GS115/pAO $\alpha-5$ ROL harboring pPIC3.5K-Ssa4-Sso2-Bmh2 & This study \\
\hline GS115/5ROL-Ssa4-Sso2-Bmh2-Bip & GS115/pAO $\alpha-5$ ROL harboring pPIC3.5K-Ssa4-Sso2-Bmh2 and pPICZ-Bip & This study \\
\hline GS115/5ROL-Ssa4-Sso2-Bmh2-Pdi & GS115/pAO $\alpha-5$ ROL harboring pPIC3.5K-Ssa4-Sso2-Bmh2 and pPICZ-Pdi & This study \\
\hline GS115/5ROL-Ssa4-Sso2-Bmh2-Hac1 & GS115/pAO $\alpha$-5ROL harboring pPIC3.5K-Ssa4-Sso2-Bmh2 and pPICZ-Hac1 & This study \\
\hline GS115/5ROL-Ssa4-Sso2-Bmh2-VHb & GS115/pAO $\alpha-5$ ROL harboring pPIC3.5K-Ssa4-Sso2-Bmh2 and pPICZ-VHb & This study \\
\hline
\end{tabular}


Table 3. Primers used for PCR in this study.

\begin{tabular}{|c|c|c|c|}
\hline Primers & Sequence $\left(5^{\prime}-3^{\prime}\right)$ & Annotation & GenBank \\
\hline Ssa4-F & CCGCTCGAGACGATGGGTAAATCAATTGGAATTG & XhoI site (underlined) & \multirow{2}{*}{ XM_002492398.1 } \\
\hline Ssa4-R & ATTTGCGGCCGCTTAATCGACTTCTTCCACGG & NotI site (underlined) & \\
\hline Bip-F & CCGCTCGAGACGATGCTGTCGTTAAAACCATCTTGG & XhoI site (underlined) & \multirow{2}{*}{ AY965684.1 } \\
\hline Bip-R & ATTTGCGGCCGCCTACAACTCATCATGATCATAGTCA & NotI site (underlined) & \\
\hline Cne1-F & ATTATTCGAAACGATGAAGATCTCTACCATTGC & AsuII site (underlined) & \multirow{2}{*}{ XM_002491173.1 } \\
\hline Cne1-R & ATTTGCGGCCGCCTAGGTTCTCTTTGTAGC & NotI site (underlined) & \\
\hline Ero1-F & ATTATTCGAAACGATGAGGATAGTAAGGAGCG & AsuII site (underlined) & \multirow{2}{*}{ XM_002489600.1 } \\
\hline Ero1-R & ATTTGCGGCCGCTTACAAGTCTACTCTATATG & NotI site (underlined) & \\
\hline Sec53-F & ATTATTCGAAACGATGTCGTTTTCTAATAAAGAAGATCC & AsuII site (underlined) & \multirow{2}{*}{ XM_002492115.1 } \\
\hline Sec53-R & $\overline{\text { ATTTGCGGCCGCTTACAGGGAAAAGAGCTCC }}$ & NotI site (underlined) & \\
\hline Bmh2-F & CTGAATTCACGATGTCAAGAGAAGATTCTG & EcoRI site (underlined) & \multirow{2}{*}{ XM_002490942.1 } \\
\hline Bmh2-R & ATTTGCGGCCGCTCACTCTTCATCTTTGGGAG & NotI site (underlined) & \\
\hline$b m-f$ & GTTATTTGGCCGAATTTGCTG & Elimination of EcoRI site & \multirow{5}{*}{ XM_002490368.1 } \\
\hline bm-r & CAGCAAATTCGGCCAAATAAC & & \\
\hline Sso2-F & CTGAATTCACGATGAGTAACCAGTATAATCC & EcoRI site (underlined) & \\
\hline Sso2-R & ATTTGCGGCCGCCTATCTTCCCCAGTTTCCG & NotI site (underlined) & \\
\hline sso-f & CTGAGACCAGTCGTCAACG & Elimination of SalI site & \\
\hline sso-r & CGTTGACGACTGGTCTCAG & & \multirow{5}{*}{ XM_002489994.1 } \\
\hline Hac1-F & CTGAATTCATGCCCGTAGATTCTTCTC & EcoRI site (underlined) & \\
\hline Hac1-R & ATTTGCGGCCGCCTATTCCTGGAAGAATACAAAGTC & NotI site (underlined) & \\
\hline ha-f & AATCGGTTGCATCATCCAGCAGCACCATTTACCGCTAATGCA & & \\
\hline ha-r & TGCATTAGCGGTAAATGGTGCTGCTGGATGATGCAACCGATT & & \\
\hline $\mathrm{VHb}-\mathrm{F}$ & CTGAATTCACCATGTTAGACCAGCAAACC & EcoRI site (underlined) & \multirow{2}{*}{ L21670.1 } \\
\hline VHb-R & ATTTGCGGCCGCTTATTCAACCGCTTGAGCG & NotI site (underlined) & \\
\hline Pdi-F & CTGAATTCATGCAATTCAACTGGAATATTAAAACTGTG & EcoRI site (underlined) & \multirow{2}{*}{ EU805807.1 } \\
\hline Pdi-R & ATTTGCGGCCGCTTAAAGCTCGTCGTGAGCGTC & NotI site (underlined) & \\
\hline gROL-F & CAAGTATGCTGGTATCGCTG & RT-PCR for $R O L$ & \multirow{6}{*}{ XM_002491300.1 } \\
\hline qROL-R & GAGTTGGTACCACGGAAAAC & RT-PCR for $R O L$ & \\
\hline qGADPH-F & CGGTGTTTTCACCACTTTGGA & RT-PCR for $G A D P H^{1}$ & \\
\hline qGADPH-R & CAACGAACATTGGAGCATCCT & RT-PCR for GADPH & \\
\hline qPdi-F & GCCGTTAAATTCGGTAAGCA & RT-PCR for $P d i$ & \\
\hline qPdi-F & TCAGCTCGGTCACATCTTTG & RT-PCR for $P d i$ & \\
\hline
\end{tabular}

The media Luria-Bertani (LB), low-salt LB, yeast extract-peptone-dextrose (YPD), buffered methanol-complex medium (BMMY), buffered glycerol-complex medium (BMGY), BMMY-rhodamine B-olive oil medium (BRBO), and the culture conditions were as described previously [14].

\subsection{Vector Construction}

The helper genes Ssa4 and Bip were amplified from the genomic DNA of P. pastoris strain GS115; the polymerase chain reaction (PCR) fragments were double-digested with XhoI and NotI, then inserted into XhoI/NotI-digested pPICZA to generate pPICZ-Ssa4 and pPICZ-Bip, respectively.

The genes Cne1, Ero1, and Sec53 were respectively cloned using the primer pairs Cne1-F/Cne1-R, Ero1-F/Ero1-R, and Sec53-F/Sec53-R, which all included AsuII/NotI-restriction sites at both ends and the chromosomal DNA of GS115 as the template. The PCR segments were digested with AsuII and NotI then transferred into pPICZA, respectively forming pPICZ-Cne1, pPICZ-Ero1, and pPICZ-Sec53.

To clone the $B m h 2$ gene and synchronously eliminate the EcoRI restriction site via synonymous mutation, the upstream and downstream parts of the $B m h 2$ gene were respectively cloned from the genomic DNA of GS115 using the primer pairs Bmh2-F/bm-r and bm-f/Bmh2-R. These two PCR products were purified, then mixed as overlap extension PCR (OE-PCR) templates, and the OE-PCR was conducted using the primer pair Bmh2-F/Bmh2-R, generating the Bmh2 gene. In order to obtain the $S s o 2$ gene and synchronously remove the SalI site in the $S s o 2$ gene, and to clone the Hac1 gene without the intron part, the $S s o 2$ and $H a c 1$ genes were amplified by OE-PCR as described for Bmh2. Additionally, the $V H b$ gene and Pdi gene were respectively amplified by PCR using the primers $\mathrm{VHb}-\mathrm{F} / \mathrm{VHb}-\mathrm{R}$ and Pdi-F/Pdi-R. These five gene fragments were double-digested with EcoRI and NotI and then cloned into the EcoRI/NotI-opened plasmid pPICZA, respectively generating pPICZ-Bmh2, pPICZ-Sso2, pPICZ-Hac1, pPICZ-VHb, and pPICZ-Pdi. 
To generate the pPIC3.5K-derived vectors, the helper gene fragments were obtained by double-digesting the pPICZA-derived plasmids with SacI and NotI and then inserting them into the SacI/NotI-treated vector pPIC3.5K. Additionally, the plasmids harboring multiple expression-related helper gene cassettes were constructed on the basis of the pPIC3.5K-derived expression vector, according to a previously described in vitro multi-copy vector construction method [14]. All plasmids were verified by DNA sequencing at Tsingke Biological Technology Co. (Wuhan, China).

\subsection{Transformation of P. Pastoris}

The plasmids were linearized using appropriate restriction enzymes before transformation. To prepare P. pastoris competent cells, an overnight culture of the host strain was grown in a $250 \mathrm{~mL}$ flask containing $100 \mathrm{~mL}$ YPD medium at $28{ }^{\circ} \mathrm{C}$ until the cell optical density at $600 \mathrm{~nm}\left(\mathrm{OD}_{600 \mathrm{~nm}}\right)$ reached 1.2-1.5. The cells were then harvested by centrifugation at $2000 \times g$ for $4 \mathrm{~min}$ and washed twice in $100 \mathrm{~mL}$ of pre-cooled sterile water. Subsequently, the pellet was resuspended twice in $20 \mathrm{~mL}$ of sterilized and cold-processed $1 \mathrm{M}$ sorbitol solution, followed by resuspension in $200 \mu \mathrm{L}$ of $1 \mathrm{M}$ sorbitol. About $2 \mu \mathrm{g}$ of the linearized plasmids were added to $80 \mu \mathrm{L}$ competent cells, then transferred into a new pre-cooled $2 \mathrm{~mm}$ electroporation cuvette (Invitrogen) for $10 \mathrm{~min}$ on ice. The cuvette was pulsed for about $5 \mathrm{~ms}$ using a Gene Pulser apparatus (Bio-Rad, Hercules, CA, USA) with the operating parameters of $1.5 \mathrm{kV}, 200 \Omega$, and $25 \mu \mathrm{F}$. Then, $1 \mathrm{~mL}$ of $1 \mathrm{M}$ sorbitol was added immediately and the cells were incubated for $1-2 \mathrm{~h}$ at $30^{\circ} \mathrm{C}$. The transformants were selected on YPD plates containing $100 \mu \mathrm{g} / \mathrm{mL}$ zeocin or $200 \mu \mathrm{g} / \mathrm{mL}$ geneticin (G418) for $2-3$ days at $28^{\circ} \mathrm{C}$.

\subsection{Recombinant Screening and Shake-Flask Culture}

Transformants with zeocin or G418 resistance were randomly picked onto BRBO plates. Soon afterwards, $200 \mu \mathrm{L}$ of absolute methanol was added every day to the culture dish. Twenty colonies with clear transparent circles were selected for incubation into a $500 \mathrm{~mL}$ flask containing $20 \mathrm{~mL}$ of BMGY medium. About one day later, the cells were gathered by centrifugation and transferred into $20 \mathrm{~mL}$ of BMMY at $27^{\circ} \mathrm{C}$. Additionally, $1.2 \%(v / v)$ methanol was added daily to the flask to induce ROL expression.

\subsection{Enzyme Assay and Total Protein Concentration}

ROL activity was determined via a titrimetry method. Four $\mathrm{mL}$ of substrate $(250 \mathrm{~mL} / \mathrm{L}$ olive oil emulsified with $20 \mathrm{~g} / \mathrm{L}$ polyvinyl alcohol solution), $5 \mathrm{~mL}$ of $50 \mathrm{mM}$ Tris- $\mathrm{HCl}$ buffer (pH 8.0), and $1 \mathrm{~mL}$ of properly diluted fermentation filtrate were mixed in a $50 \mathrm{~mL}$ flask. After incubation in a shaking water bath at $35^{\circ} \mathrm{C}$ for $10 \mathrm{~min}, 15 \mathrm{~mL}$ of absolute ethanol/acetone $(1: 1, v / v)$ was added to the mixture to stop the reaction process. The amount of released fatty acids was determined by titration with $50 \mathrm{mM} \mathrm{NaOH}$. One unit (U) of ROL activity was defined as the amount of lipase producing $1 \mu \mathrm{mol}$ of fatty acid from the substrate per $1 \mathrm{~min}$ under the hydrolysis conditions. Total protein concentration was measured as described by Bradford, using bovine serum albumin as a standard [35]. Each experiment was repeated three times.

\subsection{Gene-Copy Number Determination by RT-qPCR}

Absolute quantification to determine the gene copy number was carried out by RT-qPCR, as described previously [14]. RT-qPCR reactions were performed using a StepOnePlus instrument with StepOne software version 2.3 (Applied Biosystems, Foster City, CA, USA). The gene copy number was calculated via absolute quantification by the method described by Abad et al. [36]. 


\subsection{L Fermenter Cultivation}

The high-density fermentation was executed in a 3 L fermenter (BIOTECH-3BG-7000A; Baoxing Co., Shanghai, China). The fermentation process control and cultivation conditions followed a procedure established previously [14].

\subsection{Dry Cell Weight (DCW) and $O D_{600 \mathrm{~nm}}$}

The DCW (g/L) was determined by centrifuging $10 \mathrm{~mL}$ of fermentation broth in a pre-weighted tube at $5000 \times g$ for $10 \mathrm{~min}$, followed by drying the samples at $105^{\circ} \mathrm{C}$ to a constant. The samples were diluted with sterile water to measure the $\mathrm{OD}_{600 \mathrm{~nm}}$.

\subsection{Sodium Dodecyl Sulfate Polyacrylamide Gel Electrophoresis (SDS-PAGE) Analysis}

The polyacrylamide gel consisted of two parts: a $6 \%$ stacking gel and a $12 \%$ separating gel. SDS-PAGE analysis was conducted on a vertical mini gel apparatus (Bio-Rad, Hercules, CA, USA). The samples were stained with Coomassie Brilliant Blue R-250 (Amresco, Solon, OH, USA).

\section{Conclusions}

A series of recombinant strains containing different gene copy numbers of $R O L$ gene and Pdi gene were first constructed to investigate the effects of Pdi gene dosage on ROL production. The results showed that one copy of Pdi gene was enough for a high-level expression of ROL. On the basis of this observation, to study the effect of the co-expression of helper genes on ROL expression, we only generated strains harboring one copy of the helper genes by screening 20 recombinant colonies directly after electroporation, without a PTVA process. Some helper proteins were identified to have positive effects on ROL expression. The helper proteins Ssa4, Bmh2, and Sso2, all participating in vesicular trafficking, could strongly promote ROL expression; when combined, a further improvement in ROL production level to $5230 \mathrm{U} / \mathrm{mL}$ was obtained in the strain GS115/5ROL-Ssa4-Sso2-Bmh2 4\#. Among the remaining helper genes, which also showed a positive effect on ROL production, only the co-expression of $\mathrm{VHb}$ could further slightly increase ROL secretion to $5650 \mathrm{U} / \mathrm{mL}$ in the strain of GS115/5ROL-Ssa4-Sso2-Bmh2-VHb 9\#. Furthermore, fed-batch studies of the two optimal strains were conducted in a $3 \mathrm{~L}$ fermenter, and the maximum ROL activity obtained was 41,700 U/mL, the highest level ever reported. This study suggests that screening potential helper factors and then combining them together in a reasonable way is a feasible approach to increase a target protein expression to an extremely high level in P. pastoris.

Author Contributions: L.J. and Y.Y. designed the experiments; L.J., Q.Z., and Z.S. performed the experiments; L.J. and Y.Y. analyzed the data; L.J. and Y.Y. wrote the paper.

Funding: This work was financially supported by the National Natural Science Foundation of China (Nos: 31070089, 31170078, J1103514), the National High Technology Research and Development Program of China (Nos: 2011AA02A204, 2013AA065805, 2014AA093510), the Natural Science Foundation of Hubei Province (No. 2015CFA085), and the Fundamental Research Funds for HUST (Nos. 2014NY007, 2017KFYXJJ212, 2017KFXKJC010, 2017KFTSZZ001).

Acknowledgments: The authors would like to acknowledge the Analytical and Testing Center of HUST for their valuable assistance in protein and quantitative real-time PCR measurements.

Conflicts of Interest: The authors declare no conflict of interest. 


\section{Abbreviations}

$\begin{array}{ll}\text { Bip } & \text { immunoglobulin-binding protein } \\ \text { BMGY } & \text { buffered glycerol-complex medium } \\ \text { BMMY } & \text { buffered methanol-complex medium } \\ \text { BRBO } & \text { BMMY-rhodamine B-olive oil medium } \\ \text { Cne1 } & \text { calnexin-like protein } \\ \text { DCW } & \text { dry cell weight } \\ \text { ER } & \text { endoplasmic reticulum } \\ \text { ERAD } & \text { ER-associated degradation } \\ \text { Ero1 } & \text { ER oxidoreduction 1 } \\ \text { GOD } & \text { glucose oxidase } \\ \text { LB } & \text { Luria-Bertani } \\ \text { OD } 600 \mathrm{~nm} & \text { optical density at 600 nm } \\ \text { OE-PCR } & \text { overlap extension PCR } \\ \text { pAOX1 } & \text { alcohol oxidase 1 promoter } \\ \text { Pdi } & \text { protein disulfide isomerase } \\ \text { PTVA } & \text { posttransformational vector amplification } \\ \text { ROL } & \text { Rhizopus oryzae lipase } \\ \text { SDS-PAGE } & \text { sodium dodecyl sulfate polyacrylamide gel electrophoresis } \\ \text { UPR } & \text { unfolded protein response } \\ \text { VHb } & \text { vitreoscilla hemoglobin } \\ \text { YPD } & \text { yeast extract-peptone-dextrose }\end{array}$

\section{References}

1. Brzozowski, A.M.; Derewenda, U.; Derewenda, Z.S.; Dodson, G.G.; Lawson, D.M.; Turkenburg, J.P.; Bjorkling, F.; Huge-Jensen, B.; Patkar, S.A.; Thim, L. A model for interfacial activation in lipases from the structure of a fungal lipase-inhibitor complex. Nature 1991, 351, 491-494. [CrossRef] [PubMed]

2. Treichel, H.; de Oliveira, D.; Mazutti, M.A.; Di Luccio, M.; Oliveira, J.V. A review on microbial lipases production. Food Bioprocess Technol. 2010, 3, 182-196. [CrossRef]

3. Jaeger, K.E.; Eggert, T. Lipases for biotechnology. Curr. Opin. Biotechnol. 2002, 13, 390-397. [CrossRef]

4. Hasan, F.; Shah, A.A.; Hameed, A. Industrial applications of microbial lipases. Enzyme Microb. Technol. 2006, 39, 235-251. [CrossRef]

5. Kaieda, M.; Samukawa, T.; Matsumoto, T.; Ban, K.; Kondo, A.; Shimada, Y.; Noda, H.; Nomoto, F.; Ohtsuka, K.; Izumoto, E.; et al. Biodiesel fuel production from plant oil catalyzed by Rhizopus oryzae lipase in a water-containing system without an organic solvent. J. Biosci. Bioeng. 1999, 88, 627-631. [CrossRef]

6. Su, F.; Li, G.; Fan, Y.; Yan, Y. Enhancing biodiesel production via a synergic effect between immobilized Rhizopus oryzae lipase and Novozym 435. Fuel Process. Technol. 2015, 137, 298-304. [CrossRef]

7. Resina, D.; Maurer, M.; Cos, O.; Arnau, C.; Carnicer, M.; Marx, H.; Gasser, B.; Valero, F.; Mattanovich, D.; Ferrer, P. Engineering of bottlenecks in Rhizopus oryzae lipase production in Pichia pastoris using the nitrogen source-regulated FLD1 promoter. New Biotechnol. 2009, 25, 396-403. [CrossRef] [PubMed]

8. Yu, X.; Lu, X.; Zhao, L.; Xu, Y. Impact of $\mathrm{NH}_{4}{ }^{+}$nitrogen source on the production of Rhizopus oryzae lipase in Pichia pastoris. Process Biochem. 2013, 48, 1462-1468. [CrossRef]

9. Cereghino, J.L.; Cregg, J.M. Heterologous protein expression in the methylotrophic yeast Pichia pastoris. FEMS Microbiol. Rev. 2000, 24, 45-66. [CrossRef] [PubMed]

10. Macauley-Patrick, S.; Fazenda, M.L.; McNeil, B.; Harvey, L.M. Heterologous protein production using the Pichia pastoris expression system. Yeast 2005, 22, 249-270. [CrossRef] [PubMed]

11. Li, P.; Anumanthan, A.; Gao, X.; Ilangovan, K.; Suzara, V.V.; Duezguenes, N.; Renugopalakrishnan, V. Expression of recombinant proteins in Pichia pastoris. Appl. Biochem. Biotechnol. 2007, 142, 105-124. [CrossRef]

12. Sreekrishna, K.; Brankamp, R.G.; Kropp, K.E.; Blankenship, D.T.; Tsay, J.T.; Smith, P.L.; Wierschke, J.D.; Subramaniam, A.; Birkenberger, L.A. Strategies for optimal synthesis and secretion of heterologous proteins in the methylotrophic yeast Pichia pastoris. Gene 1997, 190, 55-62. [CrossRef] 
13. Sha, C.; Yu, X.; Lin, N.; Zhang, M.; Xu, Y. Enhancement of lipase r27RCL production in Pichia pastoris by regulating gene dosage and co-expression with chaperone protein disulfide isomerase. Enzyme Microb. Technol. 2013, 53, 438-443. [CrossRef] [PubMed]

14. Jiao, L.; Zhou, Q.; Su, Z.; Xu, L.; Yan, Y. High-level extracellular production of Rhizopus oryzae lipase in Pichia pastoris via a strategy combining optimization of gene-copy number with co-expression of ERAD-related proteins. Protein Expres. Purif. 2018, 147, 1-12. [CrossRef] [PubMed]

15. Norden, K.; Agemark, M.; Danielson, J.A.; Alexandersson, E.; Kjellbom, P.; Johanson, U. Increasing gene dosage greatly enhances recombinant expression of aquaporins in Pichia pastoris. BMC Biotechnol. 2011, 11, 47. [CrossRef] [PubMed]

16. Hohenblum, H.; Gasser, B.; Maurer, M.; Borth, N.; Mattanovich, D. Effects of gene dosage, promoters, and substrates on unfolded protein stress of recombinant Pichia pastoris. Biotechnol. Bioeng. 2004, 85, 367-375. [CrossRef] [PubMed]

17. Whyteside, G.; Alcocer, M.J.C.; Kumita, J.R.; Dobson, C.M.; Lazarou, M.; Pleass, R.J.; Archer, D.B. Native-state stability determines the extent of degradation relative to secretion of protein variants from Pichia pastoris. PLoS ONE 2011, 6, e22692. [CrossRef] [PubMed]

18. Graf, A.; Gasser, B.; Dragosits, M.; Sauer, M.; Leparc, G.G.; Tuechler, T.; Kreil, D.P.; Mattanovich, D. Novel insights into the unfolded protein response using Pichia pastoris specific DNA microarrays. BMC Genom. 2008, 9, 390. [CrossRef] [PubMed]

19. Damasceno, L.M.; Anderson, K.A.; Ritter, G.; Cregg, J.M.; Old, L.J.; Batt, C.A. Cooverexpression of chaperones for enhanced secretion of a single-chain antibody fragment in Pichia pastoris. Appl. Microbiol. Biotechnol. 2007, 74, 381-389. [CrossRef] [PubMed]

20. Gu, L.; Zhang, J.; Du, G.; Chen, J. Multivariate modular engineering of the protein secretory pathway for production of heterologous glucose oxidase in Pichia pastoris. Enzyme Microb. Technol. 2015, 68, 33-42. [CrossRef] [PubMed]

21. Xu, L.; Liu, Z.; Wang, G.; Pan, D.; Jiao, L.; Yan, Y. Overexpression of Candida rugosa lipase Lip1 via combined strategies in Pichia pastoris. Enzyme Microb. Technol. 2016, 82, 115-124. [CrossRef]

22. Gasser, B.; Sauer, M.; Maurer, M.; Stadlmayr, G.; Mattanovich, D. Transcriptomics-based identification of novel factors enhancing heterologous protein secretion in Yeasts. Appl. Environ. Microb. 2007, 73, 6499-6507. [CrossRef] [PubMed]

23. Michelsen, K.; Mrowiec, T.; Duderstadt, K.E.; Frey, S.; Minor, D.L.; Mayer, M.P.; Schwappach, B. A multimeric membrane protein reveals 14-3-3 isoform specificity in forward transport in yeast. Traffic 2006, 7, 903-916. [CrossRef] [PubMed]

24. Gasser, B.; Maurer, M.; Rautio, J.; Sauer, M.; Bhattacharyya, A.; Saloheimo, M.; Penttila, M.; Mattanovich, D. Monitoring of transcriptional regulation in Pichia pastoris under protein production conditions. BMC Genom. 2007, 8, 179. [CrossRef] [PubMed]

25. Chen, H.; Chu, J.; Zhang, S.; Zhuang, Y.; Qian, J.; Wang, Y.; Hu, X. Intracellular expression of Vitreoscilla hemoglobin improves $S$-adenosylmethionine production in a recombinant Pichia pastoris. Appl. Microbiol. Biotechnol. 2007, 74, 1205-1212. [CrossRef] [PubMed]

26. Wang, X.; Sun, Y.; Shen, X.; Ke, F.; Zhao, H.; Liu, Y.; Xu, L.; Yan, Y. Intracellular expression of Vitreoscilla hemoglobin improves production of Yarrowia lipolytica lipase LIP2 in a recombinant Pichia pastoris. Enzyme Microb. Technol. 2012, 50, 22-28. [CrossRef] [PubMed]

27. Zirpel, B.; Degenhardt, F.; Zammarelli, C.; Wibberg, D.; Kalinowski, J.; Stehle, F.; Kayser, O. Optimization of $\Delta^{9}$-tetrahydrocannabinolic acid synthase production in Komagataella phaffii via post-translational bottleneck identification. J. Biotechnol. 2018, 272-273, 40-47. [CrossRef] [PubMed]

28. Wang, X.; Shen, X.; Zhao, H.; Sun, Y.; Liu, T.; Liu, Y.; Xu, L.; Yan, Y. Combined strategies for the improvement of heterologous expression of a His-tagged Yarrowia lipolytica lipase Lip2 in Pichia pastoris. Afr. J. Biotechnol. 2011, 10, 18503-18512. [CrossRef]

29. Yu, X.; Sha, C.; Guo, Y.; Xiao, R.; Xu, Y. High-level expression and characterization of a chimeric lipase from Rhizopus oryzae for biodiesel production. Biotechnol. Biofuels 2013, 6, 29. [CrossRef] [PubMed]

30. Delic, M.; Goengrich, R.; Mattanovich, D.; Gasser, B. Engineering of protein folding and secretion-strategies to overcome bottlenecks for efficient production of recombinant proteins. Antioxid. Redox Signal. 2014, 21, 414-437. [CrossRef] [PubMed] 
31. Schwarzhans, J.; Wibberg, D.; Winkler, A.; Luttermann, T.; Kalinowski, J.; Friehs, K. Integration event induced changes in recombinant protein productivity in Pichia pastoris discovered by whole genome sequencing and derived vector optimization. Microb. Cell Fact. 2016, 15, 84. [CrossRef] [PubMed]

32. Romanos, M.; Scorer, C.; Sreekrishna, K.; Clare, J. The generation of multicopy recombinant strains. In Pichia Protocols; Higgins, D.R., Cregg, J.M., Eds.; Humana Press: New York, NY, USA, 1998; Volume 103, pp. 55-72, ISBN 978-1-59259-578-5.

33. Sunga, A.J.; Tolstorukov, I.; Cregg, J.M. Posttransformational vector amplification in the yeast Pichia pastoris. FEMS Yeast Res. 2008, 8, 870-876. [CrossRef] [PubMed]

34. Jiao, L.; Zhou, Q.; Liu, W.; Yan, Y. New insight into the method of posttransformational vector amplification (PTVA) in Pichia pastoris. J. Microbiol. Meth. 2018, 148, 151-154. [CrossRef] [PubMed]

35. Bradford, M.M. A rapid and sensitive method for the quantitation of microgram quantities of protein utilizing the principle of protein-dye binding. Anal. Biochem. 1976, 72, 248-254. [CrossRef]

36. Abad, S.; Kitz, K.; Hoermann, A.; Schreiner, U.; Hartner, F.S.; Glieder, A. Real-time PCR-based determination of gene copy numbers in Pichia pastoris. Biotechnol. J. 2010, 5, 413-420. [CrossRef] [PubMed]

(C) 2018 by the authors. Licensee MDPI, Basel, Switzerland. This article is an open access article distributed under the terms and conditions of the Creative Commons Attribution (CC BY) license (http://creativecommons.org/licenses/by/4.0/). 